\title{
Corrigendum: The development of trunk control and its relation to reaching in infancy: a longitudinal study
}

\author{
Jaya Rachwani ${ }^{1 *}$, Victor Santamaria ${ }^{1}$, Sandra L. Saavedra ${ }^{2}$ and Marjorie H. Woollacott ${ }^{1}$ \\ ${ }^{1}$ Department of Human Physiology and Institute of Neuroscience, University of Oregon, Eugene, OR, USA, ${ }^{2}$ Department of \\ Rehabilitation Sciences, University of Hartford, West Hartford, CT, USA
}

Keywords: infant development, independent sitting, posture, trunk control, reaching, EMG

\section{A corrigendum on}

The development of trunk control and its relation to reaching in infancy: a longitudinal study by Rachwani, J., Santamaria, V., Saavedra, S. L., and Woollacott, M. H. (2015). Front. Hum. Neurosci. 9:94. doi: 10.3389/fnhum.2015.00094

Figure 4 of the article by Rachwani et al. (2015) contained a minor error, which we hereby rectify. In the original figure, the graph displaying the number of movement units across sitting development is incorrect (bottom graph on the left column). We therefore re-submit Figure 4 with the correct

\section{OPEN ACCESS}

Edited and reviewed by: Gavin Buckingham, Heriot-Watt University, UK

${ }^{*}$ Correspondence: Jaya Rachwani, rachwani@uoregon.edu

Received: 27 June 2015 Accepted: 01 July 2015 Published: 21 July 2015

Citation:

Rachwani J, Santamaria V, Saavedra

SL and Woollacott MH (2015)

Corrigendum: The development of trunk control and its relation to reaching in infancy: a longitudinal study. Front. Hum. Neurosci. 9:406.

doi: 10.3389/fnhum.2015.00406 graph. We sincerely apologize for the inconvenience.

\section{Acknowledgments}

This work was supported by the National Institutes of Health Grant 1R01HD062745-01, MW, principal investigator, and by the Eugene Evonuk Memorial Graduate Fellowship for JR.

\section{References}

Rachwani, J., Santamaria, V., Saavedra, S. L., and Woollacott, M. H. (2015). The development of trunk control and its relation to reaching in infancy: a longitudinal study. Front. Hum. Neurosci. 9:94. doi: 10.3389/fnhum.2015.00094

Conflict of Interest Statement: The authors declare that the research was conducted in the absence of any commercial or financial relationships that could be construed as a potential conflict of interest.

Copyright $\odot 2015$ Rachwani, Santamaria, Saavedra and Woollacott. This is an open-access article distributed under the terms of the Creative Commons Attribution License (CC BY). The use, distribution or reproduction in other forums is permitted, provided the original author(s) or licensor are credited and that the original publication in this journal is cited, in accordance with accepted academic practice. No use, distribution or reproduction is permitted which does not comply with these terms. 

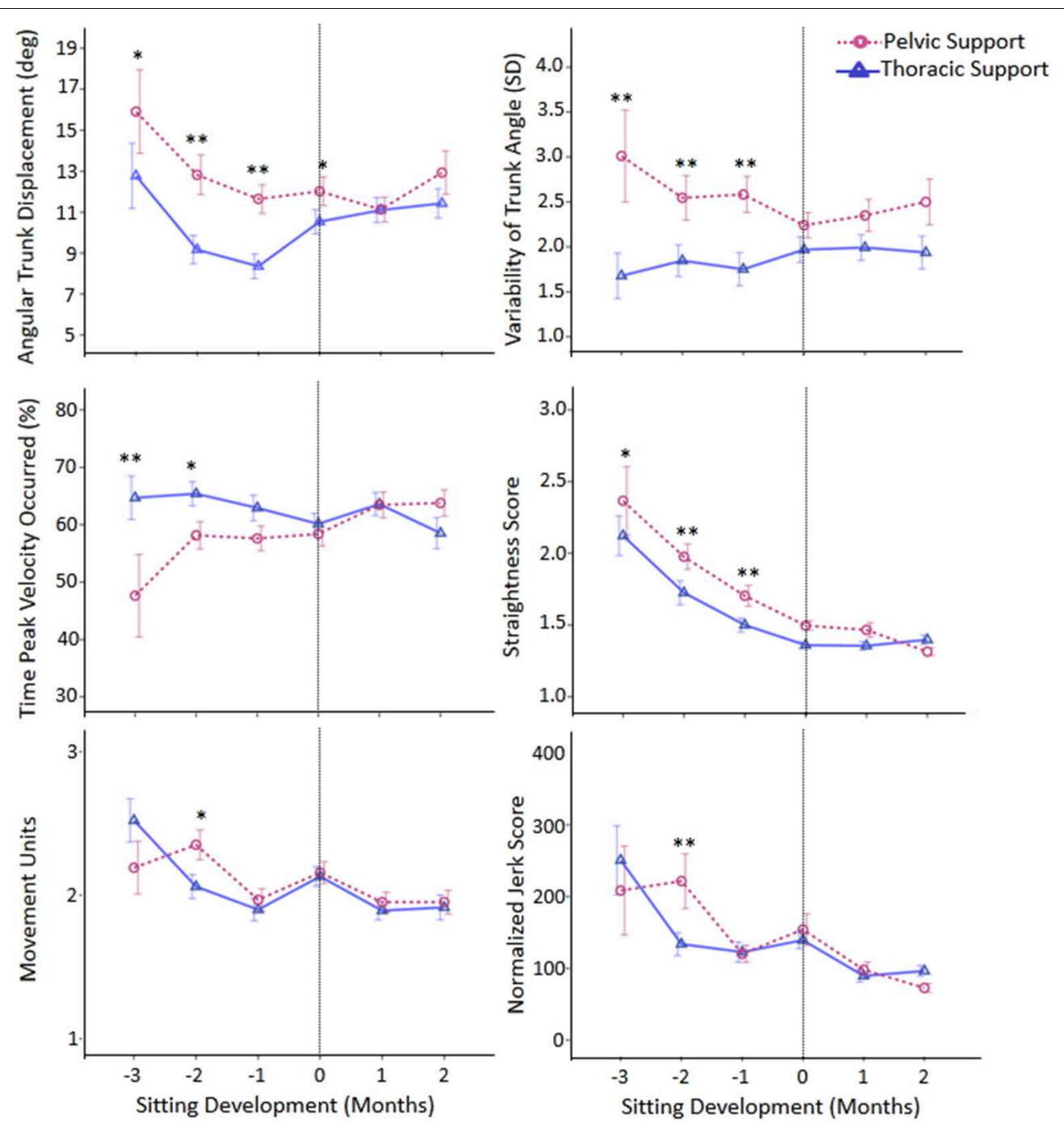

FIGURE 4 | Estimated means of group data across sitting ${ }^{*} p \leq 0.05,{ }^{* *} p<0.01$. 